\title{
AN EXPERIMENTAL STUDY OF AIR FLOW AND HEAT TRANSFER OVER IN-LINE FLAT TUBE BANK
}

\author{
Tahseen Ahmad Tahseen ${ }^{1,3}$, M. M. Rahman ${ }^{1,2}$ and M. Ishak ${ }^{1,2}$ \\ ${ }^{1}$ Faculty of Mechanical Engineering, Universiti Malaysia Pahang \\ 26600 Pekan, Pahang, Malaysia \\ Phone: +609-424-2246; Fax: +609-424-2202 \\ Email: mustafizur@ump.edu.my \\ ${ }^{2}$ Automotive Engineering Centre, Universiti Malaysia Pahang, \\ 26600 Pekan, Pahang, Malaysia \\ ${ }^{3}$ Department of Mechanical Engineering, College of Engineering, \\ Tikrit University, Tikrit, Iraq \\ *E-mail: tahseen444@gmail.com
}

\begin{abstract}
An experimental study was made to investigate heat transfer and air flow around the flat tubes of in-line flat tube banks with laminar forced convection. Measurements were conducted for sixteen tubes in the flow direction; four rows of four tubes, three air velocities $(0.6,0.8$ and $1.0 \mathrm{~m} / \mathrm{s})$ and Reynolds numbers $\mathrm{Re}_{\mathrm{Dh}}=527,703$ and 880, where $D_{\mathrm{h}}$ is the hydraulic diameter of the tube. The total heat flux supplied in all the tubes was 968,2259 and $3630 \mathrm{~W} / \mathrm{m}^{2}$, respectively. The study results indicate that the average Nusselt number of all the flat tubes increased by $23.7 \%-36.7 \%$ with Reynolds numbers varying from 527 to 880 with fixed heat flux; also the average Nusselt number increased by $11.78 \%-23.75 \%$ at varying heat fluxes of 968,2259 and $3630 \mathrm{~W} / \mathrm{m}^{2}$, respectively at Reynolds number $R e=703$. In addition, the pressure drop decreased with the increase of Reynolds number. The Nusselt number-Reynolds number correlation was found to be $N u=C_{1} \times R e^{C_{2}}$ and the correlation yielded good predictions of the measured data with the mean error $R^{2}=99.2 \%$.
\end{abstract}

Keywords: Heat transfer; forced convection; in-line flat tube; laminar flow; Reynolds number.

\section{INTRODUCTION}

The heat transfer and fluid flow in tube bundles represent an idealization of many industrially important processes. Tube banks are openly employed in cross-flow heat exchangers, whose design still relies on empirical correlations of pressure drop and heat transfer. Heat exchangers with tube bundles in cross-flow are of a major operations interest in many chemical and thermal engineering processes (Al- Doori, 2011; Aziz Hairuddin, Wandel, \& Yusaf, 2013; Buyruk, Johnson, \& Owen, 1998; Incropera, Lavine, \& DeWitt, 2011; Kaptan, Buyruk, \& Ecder, 2008; Liang \& Papadakis, 2007; Mandhani, Chhabra, \& Eswaran, 2002; Naga Sarada, Sita Rama Raju, Kalyani Radha, \& Syam Sunder, 2012; Syam Sundar \& Sharma, 2011; Wang, Penner, \& Ormiston, 2000; Zukausras, 1973). Flat tubes, however, have not been developed to the same extent, although they play a significant role in many technical applications, such as 
automotive radiators and modern heat exchangers (Vijaya Lakshmi, Subrahmanyam, Dharma Rao, \& Sharma, 2011). Designs have recently been provided that use air conditioning for automotive evaporators and condensers. Recent developments in automotive aluminum manufacturing technology have made the cost of building flat tube heat exchangers more propitious (Muthucumaraswamy \& Velmurugan, 2013; Naga Sarada et al., 2012; Rao et al., 2011; Sahin, Manay, \& Ozceyhan, 2013; Suryanarayana, Srinivasa Rao, Reddy Prasad, Sharma, \& Sarma, 2011; Webb \& Kim, 2005). In addition, flat tube heat exchangers are expected to provide the best air-side heat transfer coefficients and minimum air-side pressure drop compared with circular tube heat exchangers; the pressure drop in flat tubes is expected to be less than in circular tubes due to a smaller wake area. For the same reason, noise and vibration are expected to be less in flat tube heat exchangers than in circular tube heat exchangers.

Ay, Jang, and Yeh (2002) presented an experimental study of plate finned-tube heat exchangers. Tests were conducted on the strategic zone of both staggered and inline configurations. The results show that the average heat transfer coefficient of the staggered arrangement is $14 \%-32 \%$ greater than that of the in-line arrangement. In the experimental and numerical study of the laminar heat transfer and fluid flow over the cylinder in cross-flow presented by Buyruk et al. (1998), variations of local pressure drop, Nusselt number, streamline contour and isotherm line contour were expected with the two Reynolds numbers of 120 and 390. In addition, the results show that increasing Reynolds number causes a state of separation to move upstream and overall heat transfer to increase. Heat transfer and fluid flow over a four-row elliptic finned-tube heat exchanger was studied numerically and experimentally by Jang and Yang (1998). The change values of inlet velocity ranged from $2 \mathrm{~m} / \mathrm{s}-7 \mathrm{~m} / \mathrm{s}$. The arrangements tested were in-line and staggered elliptic finned tubes and one circular finned tube with a staggered configuration. The experimental results show that the average heat transfer coefficient increased by $35 \%-50 \%$ for the elliptical finned tube compared with an identical circular finned tube. The pressure drop in the elliptic finned-tube bundle was only $25 \%-30 \%$ of the circular finned-tube bundle array. An experimental study was carried out to investigate heat transfer and flow characteristics of one tube within a staggered tube bundle and a row of similar tubes. Variations of the local Nusselt number and local pressure coefficients were shown with different blockages and Reynolds numbers (Hussein, Sharma, Bakar, \& Kadirgama, 2013; Matos, Vargas, Laursen, \& Bejan, 2004; Muthucumaraswamy \& Velmurugan, 2013; Rao et al., 2011; Tahseen, Ishak, \& Rahman, 2012). This is an experimental, numerical and analytical study of the optimal spacing between cylinders in cross-flow forced convection. In the first part, with an experimental $R e_{D}$ range of 50-4000 and the second part, similar results were developed based on numerical simulations for $\operatorname{Pr}=0.72$ and $40 \leq \operatorname{Re}_{D} \leq 200$. The experimental and numerical results for optimal spacing and maximum thermal conductance were explained and correlated analytically by intersecting the smallspacing and large-spacing asymptotes of the thermal conductance function (Stanescu, Fowler, \& Bejan, 1996). Tahseen et al. (2012); Tahseen, Ishak, \& Rahman (2013a, 2013b) conducted numerical studies of incompressible, steady state flow and using the body fitted coordinate (BFC). The first was a study of heat transfer over a series of flat tubes between two parallel plates, while the second and third studies examined the heat transfer over the in-line and staggered configurations of a circular tube, respectively. All their studies show the effect of the Reynolds number on the Nusselt number; also, the Nusselt number consistently increases with an increase of Reynolds number. The third study shows the maximum Nusselt number at the first tube in comparison with other 
tubes. The flow over banks of elliptic cylinders was presented by Yianneskis, Papadakis, Balabani, and Castiglia (2001) both numerically and experimentally. The average velocities for the array were found experimentally by flow visualization and using a laser Doppler anemometer (Akcil \& Koldas, 2006). The results show that the arrangement generates much lower turbulence levels than an equivalent array with circular cylinders. The turbulence levels remain nearly constant along the flow sections across successive rows, reflecting the absence of confusion between adjacent columns. The experiment studied the heat transfer and pressure drop of staggered flat tube banks. The Reynolds number varied from 373 to 623 and the heat flux supplied ranged between 967.92 and 3629.7. The pressure drop increased and the dimensionless pressure drop decreased with increased Reynolds number. The study result shows that the average Nusselt number increased by $11.46 \%-46.42 \%$ (Ishak, Tahseen, \& Rahman, 2013). In a recent study, numerical research was conducted by Tahseen, Ishak, and Rahman (2014) for the heat transfer and pressure drop of air flow over the in-line arrangement of the flat tube bank. They used a neuro-fuzzy inference system (ANFAS) model to predict the values of the heat transfer coefficient and pressure drop. They examined four transverse pitches: $1.5,2.5,3.5$ and 4.5, and three longitudinal pitches: 3 , 4 and 6, for Reynolds numbers ranging from 10 to 320. Their results were offered in the form of temperature contours, streamlines, average Nusselt number and dimensionless pressure drop. The key results from this study indicated that the average deviation between the numerical and ANFIS model values for average Nusselt number is $1.9 \%$, and the dimensionless pressure drop is $2.97 \%$. In the present study, the cooling process was experimentally examined using an array of in-line flat tube banks of diameter ratio 1.85. The external flow of air with the Reynolds number, based on the mean free stream air velocity and outer hydraulic of the tube, varied from 527 to 880 . The heat flux supply to all tubes was in the range $968-3630 \mathrm{~W} / \mathrm{m}^{2}$. The aim was to detect the effects of Reynolds number on the air pressure drop across the flat tube banks and heat transfer rate.

\section{EXPERIMENTAL DETAILS}

The flat tube arrangement was made from aluminum with the smaller diameter $10 \mathrm{~mm}$ and bigger diameter $18.5 \mathrm{~mm}$, with a tube thickness of $1 \mathrm{~mm}$ and hydraulic diameter $D_{h}$ $=13.5 \mathrm{~mm}$; all tubes were $200 \mathrm{~mm}$ long. Double electric heaters were inserted inside the tubes to simulate the heat flux originating from a hot fluid. The arrangement was four rows of four tubes aligned in the direction of the external flow. The sixteen flat tubes were then assembled according to the design presented in Figure 1, in a drawer made of Teflon type polytetrafluoroethylene (PTFE), as the test module. Losses were minimized by holding the end of the flat tube between two Teflon walls at a separation of $L=200 \mathrm{~mm}$. Thirty-two heating elements consisting of cylindrical electric heaters were used, each rated at $50 \mathrm{~W}$ up to $850 \mathrm{~W}$ with $220 \mathrm{~V} \mathrm{AC}$, and with an outside diameter $8 \mathrm{~mm}$ and a length of $200 \mathrm{~mm}$. The diameter was small enough to be inserted in the aluminum tubes. The heaters were connected in parallel and the two AC variable voltage sources produced voltages in the range $0-125 \mathrm{~V}$, with maximum power supply $220 \mathrm{~V}$ and a maximum current of $2.5 \mathrm{~A}$ (model Loadstar 850). The current and voltage measurements were performed with a current clamp meter model U1191A and volt measurement meter model Tenma 9272, respectively. Fifteen thermistors of type EPCOS B57164K0102J NTC (resistance $1000 \Omega$ at $25^{\circ} \mathrm{C}$ ) were placed in the test module. All the thermistors were placed in the middle between the side walls of the 
wind tunnel and on the midline of the channels. Four thermistors were placed at the arrangement inlet $\left(T_{i n, 1}-T_{i n, 4}\right)$, four on the surfaces of the tubes $\left(T_{s, 1}-T_{s, 4}\right)$, and five at the outlet $\left(T_{\text {out }, 1}-T_{\text {out }, 5}\right)$ in one elemental channel. An additional thermistor $\left(T_{\text {bef }}\right)$ was placed on the extended region $400 \mathrm{~mm}$ ahead of the test module to measure the temperature of the free stream.

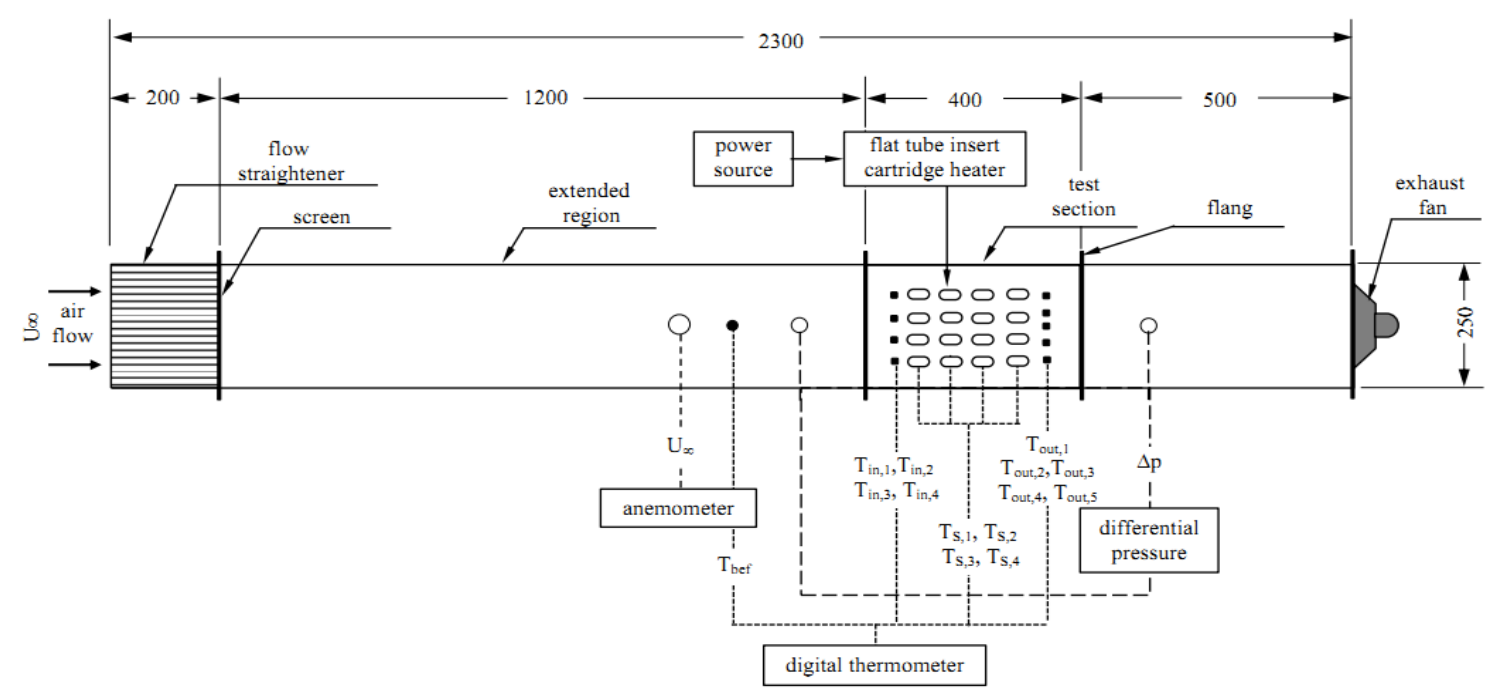

Figure 1. Schematic display of the experimental approach.

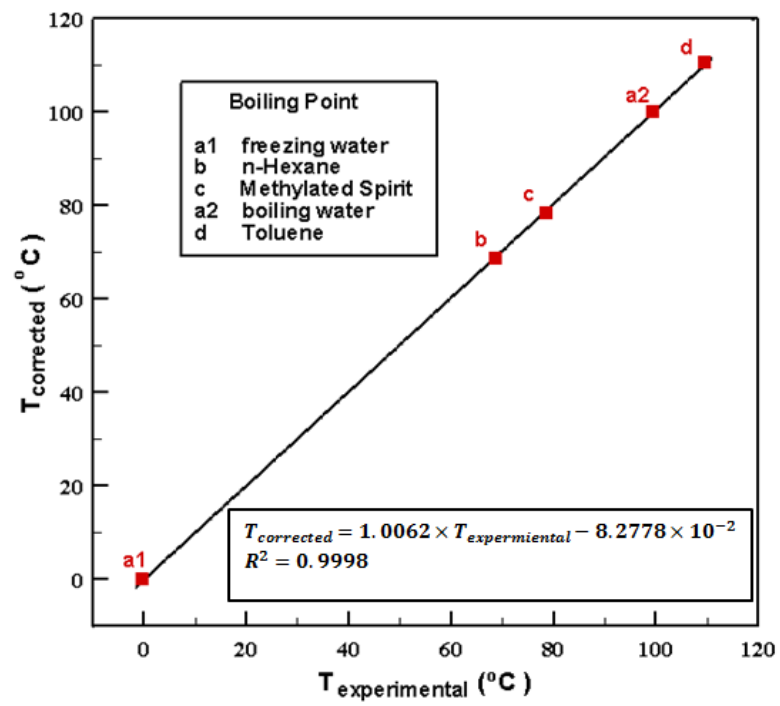

Figure 2. A typical thermistor calibration.

The thermistors on the surfaces of the tubes showed that the difference between the tubes in one elemental channel is negligible, and within a $\pm 0.57{ }^{\circ} \mathrm{C}$ margin with respect to the averaged four thermistors. Finally, the thermistor located in the extended region for the purpose of measuring the free stream temperatures recorded temperatures within a $\pm 0.22{ }^{\circ} \mathrm{C}$ margin with respect to the average temperature measured at the inlet arrangement, in all the tests carried out in this work. The velocity measurements were taken with a vane type hot wire anemometer, model $\mathrm{YK}-2004 \mathrm{AH}$, that was placed in the extended flow region, as can be seen in Figure 1. The air velocities measured 
ranged from $0.2-20 \mathrm{~m} / \mathrm{s}$. The resolution $0.1 \mathrm{~m} / \mathrm{s}$ of reading and uncertainty in free stream velocity $U_{\infty}$ was $\pm(1 \%-5 \%+0.1 \mathrm{~m} / \mathrm{s})$. The velocity of free stream $U_{\infty}$ varied within $0.6-1.0 \mathrm{~m} / \mathrm{s}$ in this study. The pressure drop measurements were taken with a differential pressure meter, model Testo 510 (Testo, Inc.). With the nominal range from 0 to $1000 \mathrm{~Pa}$, the differential pressure resolution was $1 \mathrm{~Pa}$ of reading with an accuracy of $\pm 0.3 \mathrm{~Pa}$.

The differential pressure measurements had the objective of measuring the pressure drop across each change of the free stream velocity in all experiments, as shown in Figure 1. The experimental work includes acquiring the temperature data using a highly accurate thermometer, model Testo 110 (Testo, Inc.). The range of temperatures measured was between $-50{ }^{\circ} \mathrm{C}$ and $+150{ }^{\circ} \mathrm{C}$ with a resolution of $0.1{ }^{\circ} \mathrm{C}$ of reading and accuracy $\pm 0.2{ }^{\circ} \mathrm{C}$. In addition, the thermistor was calibrated to find the deviation limits. The thermistor was immersed in four liquids: distilled water, $\mathrm{n}-$ Hexane, methylated spirit and toluene. After that, each liquid was heated separately to boiling point and then the values were recorded as shown in Figure 2 (Collett \& Hope, 1983). Each run was started by selecting the voltage and current for the cartridge heaters and air velocity of the free stream. Then we waited for 2.5-3.0 hours for the purpose of monitoring the changes in voltage, current, $T_{b e f}, T_{i n, 1}-T_{i n, 4}, T_{s, 1}-T_{s, 4}$ and $T_{\text {out }, 1}-T_{\text {out }, 5}$. We took final readings when the relative changes in the voltage, current and temperature were less than $0.5-0.8 \%, 2.0-2.2 \%$ and $0.044-0.075 \%$, respectively. These relative changes were estimated by repeating the same $\operatorname{Re}_{\mathrm{Dh}}$ value, for $7.5-9$ hours. It should be noted that these relative changes are small compared with the uncertainties in the relevant measurements.

\section{GOVERNING EQUATIONS}

In this experiment we assumed steady state flow. For the investigation we used the following relations of the relevant properties of air for the calculations, based on data from Rogers and Mayhew (2004) and valid for the temperature range of $275 \mathrm{~K} \leq 0.5\left(\overline{T_{1 \mathrm{n}}}+\overline{T_{\mathrm{s}}}\right) \leq 375 \mathrm{~K}$ :

$$
\left.\begin{array}{ll}
\rho_{\mathrm{f}}=2.209-3.414 \times 10^{-3}\left(\frac{\overline{T_{\mathrm{ln}}}+\overline{T_{\mathrm{s}}}}{2}\right), & \mathrm{kg} / \mathrm{m}^{3} \\
c_{P_{\mathrm{f}}}=\left[9.848+6.76 \times 10^{-4}\left(\overline{\frac{T_{\mathrm{nn}}}{2} \overline{T_{\mathrm{s}}}}\right)\right] \times 10^{2}, & \mathrm{~J} /(\mathrm{kg} \mathrm{K}) \\
k_{\mathrm{f}}=\left[3.479+7.58 \times 10^{-2}\left(\frac{\overline{T_{\mathrm{ln}}}+\overline{T_{\mathrm{s}}}}{2}\right)\right] \times 10^{-3}, & \mathrm{~W} /(\mathrm{m} \mathrm{K}) \\
\mu_{\mathrm{f}}=\left[4.475+4.564 \times 10^{-2}\left(\frac{\overline{T_{\mathrm{ln}}}+\overline{T_{\mathrm{s}}}}{2}\right)\right] \times 10^{-6}, & \mathrm{~kg} /(\mathrm{m} \mathrm{s})
\end{array}\right\}
$$

where

$$
\overline{T_{\mathrm{ln}}}=\frac{1}{n} \sum_{i=1}^{n}\left(T_{\mathrm{in}}\right)_{\mathrm{i}}, \quad n=4 ; \overline{T_{\mathrm{w}}}=\frac{1}{n} \sum_{i=1}^{n}\left(T_{\mathrm{s}}\right)_{\mathrm{i}}, \quad n=4
$$


The electrical heat gain rate was calculated by:

$$
Q_{\text {elect }}=V \times I
$$

The steady state heat balance of the electrically heated test surface can be written as:

$$
Q_{\text {elect }}=Q_{\text {conduction }}+Q_{\text {convection }}+Q_{\text {radiation }}
$$

For heat transfer from the system: (i) conduction between the lab and wall of the tubes was neglected because of the extremely low thermal conductivity of air $\left(0.23 \mathrm{~W} /\left(\mathrm{m}^{\circ} \mathrm{C}\right)\right)$ of Teflon and the negligible temperature difference between the lab and outer walls of the Teflon; (ii) radiation heat transfer between the surfaces of the tubes and the surroundings was also neglected. Based on the measurement of $0.5\left(\overline{T_{1 \mathrm{n}}}+\right.$ $\overline{T_{\text {out }}}$ ) and mean $\overline{T_{\mathrm{s}}}$ the radiation transfer coefficients were estimated as (Khan, Fartaj, \& Ting, 2004):

$$
\overline{h_{\text {rad }}}=\varepsilon \times \sigma \times\left[\left\{\left(\overline{T_{\text {in }}+\overline{T_{\text {out }}}}\right)^{2}+\left(\overline{T_{\mathrm{s}}}\right)^{2}\right\} \times\left\{\left(\overline{\frac{T_{\text {ln }}}{2} \overline{T_{\text {out }}}}\right)+\overline{T_{\mathrm{s}}}\right\}\right]
$$

where

$$
\overline{T_{\text {out }}}=\frac{1}{n} \sum_{i=1}^{n}\left(T_{\text {out }}\right)_{\mathrm{i}}, \quad n=5
$$

For a commercial aluminum tube with emissivity $\varepsilon \approx 0.028$ (Collett \& Hope, $1983), \overline{h_{\text {rad }}}$ was found to range between $(0.174-0.205) \mathrm{W} /\left(\mathrm{m}^{2}{ }^{\circ} \mathrm{C}\right)$, in approximately $0.0102-0.15 \%$ from convection heat transfer coefficient $\bar{h}$. Thus, the heat transfer between the air and the surface of the tubes was actually due to convection and the mechanism of Eq. (3) was rewritten (Naik, Probert, \& Shilston, 1987):

$$
Q_{\text {convection }} \cong Q_{\text {elect }}=\bar{h} A_{\mathrm{s}}\left[\overline{T_{\mathrm{s}}}-\left(\frac{\overline{T_{\mathrm{ln}}}+\overline{T_{\text {out }}}}{2}\right)\right]
$$

can be employed with

$$
A_{\mathrm{s}}=n_{\mathrm{t}} \times[\pi d+2 \times(D-d)] \times L
$$

where $n_{\mathrm{t}}$ is the number of tubes.

The mean inlet air temperature $\overline{T_{1 n}}$ varied in the range $22.86-26.01{ }^{\circ} \mathrm{C}$ and the average temperature of the surfaces of tubes $\overline{T_{\mathrm{s}}}$. For the steady state condition, the overall heat transfer rate was equal to the electrical heat supply, $Q_{\text {elect }}$. From Eq. (5), the average heat transfer coefficient was determined as:

$$
\bar{h}=\frac{Q_{\text {elect }}}{A_{\mathrm{s}}\left[\overline{T_{\mathrm{s}}}-\left(\frac{\overline{T_{\mathrm{ln}}}+\overline{T_{\text {out }}}}{2}\right)\right]}
$$


The dimensionless average heat transfer coefficient of air, namely, the Nusselt number, was calculated via Eq. (7):

where

$$
\overline{\mathrm{Nu}_{D_{\mathrm{h}}}}=D_{\mathrm{h}} \frac{\bar{h}}{k_{\mathrm{f}}}
$$

$$
D_{\mathrm{h}}=4 \times \frac{\text { cross }- \text { sectional area }}{\text { wetted perimeter }}=4 \times \frac{\left[\frac{\pi}{4} D^{2}+(D-d) d\right]}{\pi d+2(D-d)}
$$

The Reynolds number $\left(\operatorname{Re}_{\mathrm{D}_{h}}\right)$, defined in terms of the hydraulic diameter $\left(D_{\mathrm{h}}\right)$, is obtained as

$$
\operatorname{Re}_{\mathrm{D}_{h}}=U_{\infty} \times D_{\mathrm{h}} \times \frac{\rho_{\mathrm{f}}}{\mu_{\mathrm{f}}}
$$

The estimation of the Colburn $j$-factor is presented by the following nondimensional parameter:

$$
\mathrm{j}=\frac{\overline{\mathrm{Nu}_{\mathrm{Dh}_{\mathrm{h}}}}}{\operatorname{Re}_{\mathrm{Dh}_{\mathrm{h}}} \times \operatorname{Pr}^{1 / 3}}
$$

The dimensionless pressure drop is as follows:

$$
C P=\frac{\Delta P}{0.5 \times n \times \rho_{\mathrm{f}} \times U_{\infty}^{2}}
$$

where $n$ is the number of tube rows.

The experimental uncertainty issues have been dealt with elsewhere (Dieck, 1997; Holman, 2012; Kim, Simon, \& Viskanta, 1993). There is more than one way to estimate the uncertainty in the experimental results, as has been presented by Kline and McClintock (1953), who give a few sample calculations, using independent parameters (such as dimensions, temperature, velocity, etc.). They found different prejudices $(P)$ and accuracy errors $(A)$ using the root sum square (Persson, Hogmark, \& Bergström, 2005) method:

$$
P=\left[P_{1}^{2}+P_{2}^{2}+P_{3}^{2}+\cdots+P_{\mathrm{n}}^{2}\right]^{1 / 2}
$$

and

$$
A=\left[A_{1}^{2}+A_{2}^{2}+A_{3}^{2}+\cdots+A_{\mathrm{n}}^{2}\right]^{1 / 2}
$$

For the sum of component errors to get their $95 \%$ certitude uncertainty $(U)$, the following equation was used:

$$
U=\left[P^{2}+A^{2}\right]^{1 / 2}
$$

The dependent parameters (like $\mathrm{D}_{h}, \mathrm{Re}_{\mathrm{D}_{h}}, Q_{\text {elect }}, \overline{\mathrm{Nu}_{\mathrm{D}_{h}}}$, etc.) are independent functions of other measured parameters, and the uncertainty of the independent variable 
spreads in them according to their functional relationship. For example, in the case of electric power $\left(Q_{\text {elect }}\right)$ :

$$
Q_{\text {elect }}=V \times I
$$

The uncertainties of current and voltage propagate into $Q_{\text {elect }}$, and can be estimated in terms of relative or absolute values (\%) as follows:

relative

$$
\left(\frac{U_{Q_{\text {elect }}}}{Q_{\text {elect }}}\right)=\sqrt{\left(\frac{U_{\mathrm{V}}}{V}\right)^{2}+\left(\frac{U_{\mathrm{I}}}{I}\right)^{2}}
$$

or absolute

$$
\left(\frac{U_{Q_{\text {elect }}}}{Q_{\text {elect }}}\right)=\sqrt{\left(\frac{\partial Q_{\text {elect }}}{\partial V} U_{\mathrm{V}}\right)^{2}+\left(\frac{\partial Q_{\text {elect }}}{\partial I} U_{\mathrm{I}}\right)^{2}}
$$

The uncertainties in finding the $Q_{\text {elect }}, \mathrm{D}_{h}, \mathrm{Re}_{\mathrm{D}_{h}}, \overline{\mathrm{Nu}_{\mathrm{D}_{h}}}, j$, and CP were estimated and found to remain approximately within $\pm 1.6 \%, \pm 1.14 \%, \pm 8.42 \%, \pm 8.41 \%$, $\pm 7.74 \%$ and $\pm 3.5 \%$, respectively.

\section{RESULTS AND DISCUSSION}

This section presents the experimental result of laminar forced convection heat transfer across tube bundles with in-line arrays. It also discusses the effects of total heat flux and Reynolds number on the Nusselt number, pressure drop and the dimensionless pressure drop. The main objective of this study is to determine the relationship between the Reynolds number and Nusselt number. The effect of the total heat flux supply on the Nusselt number, $\overline{\mathrm{Nu}_{\mathrm{D}_{h}}}$ at different Reynolds numbers, $\mathrm{Re}_{\mathrm{D}_{h}}$ is shown in Figure 3. It can be observed that the $\overline{\mathrm{Nu}_{\mathrm{D}_{h}}}$ number increases nearly linearly with increasing total heat flux supply. In addition, the biggest value of the $\overline{\mathrm{Nu}_{\mathrm{D}_{h}}}$ number is observed at the maximum value of the $\operatorname{Re}_{\mathrm{D}_{h}}$ number. Figure 4 shows the variations of the mean Nusselt number with Reynolds number for different heat flux supply. It is clear that the $\overline{\mathrm{Nu}_{\mathrm{D}_{h}}}$ number increases almost linearly with increase of the $\operatorname{Re}_{\mathrm{D}_{h}}$ number.

Figure 5 shows the variation of the Colburn $j$-factor with Reynolds number for all cases of heat flux supplied. From the figure, the Colburn $j$-factor decreases with increasing Reynolds number for all heat flux levels supplied. It can be seen from this figure that the Colburn $j$-factor increases with increase of the heat flux supply. This is due to the heat transfer coefficient increasing with increase of the heat flux supplied. The Nusselt number depends on the heat transfer coefficient. 


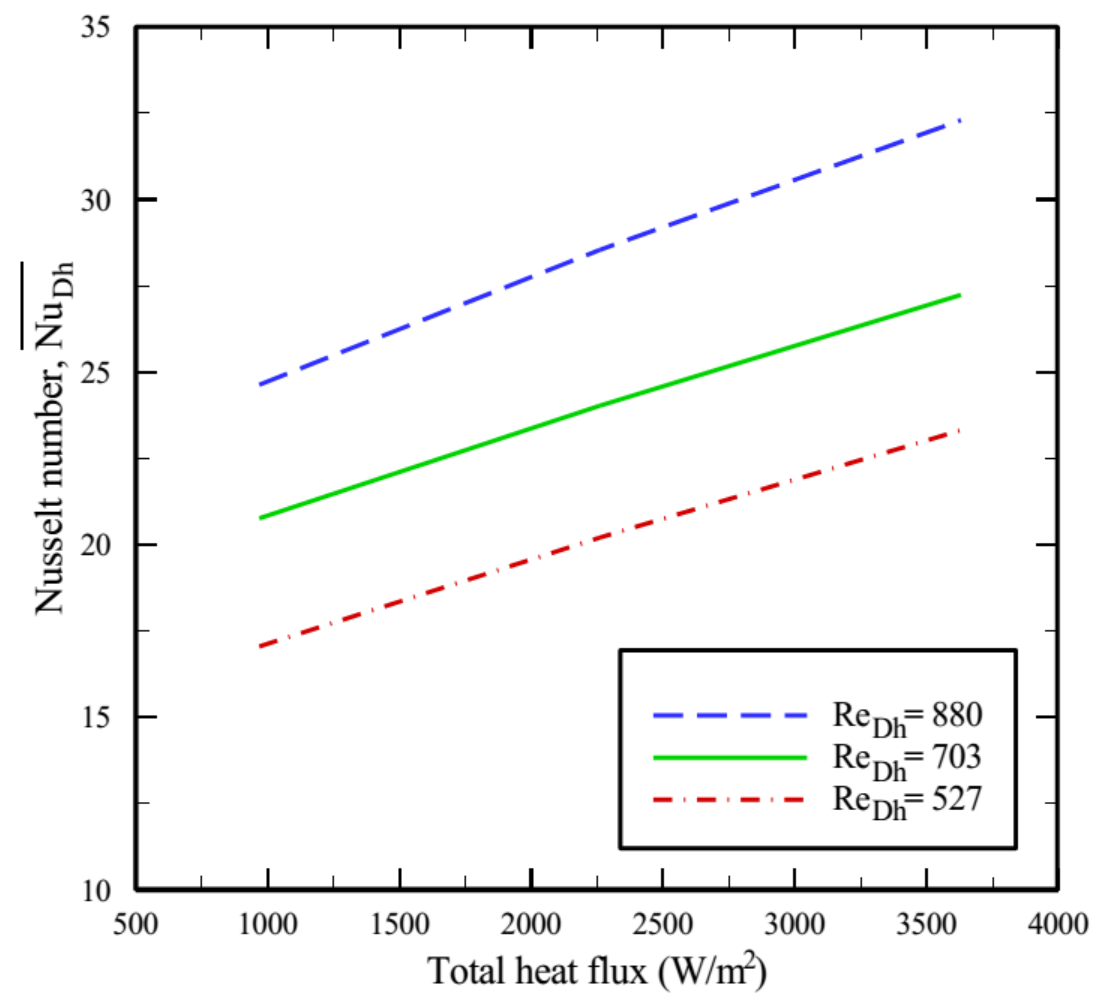

Figure 3. Effect of total heat flux on $\overline{\mathrm{Nu}_{\mathrm{D}_{h}}}$ numbers with various $\operatorname{Re}_{\mathrm{D}_{h}}$ numbers.

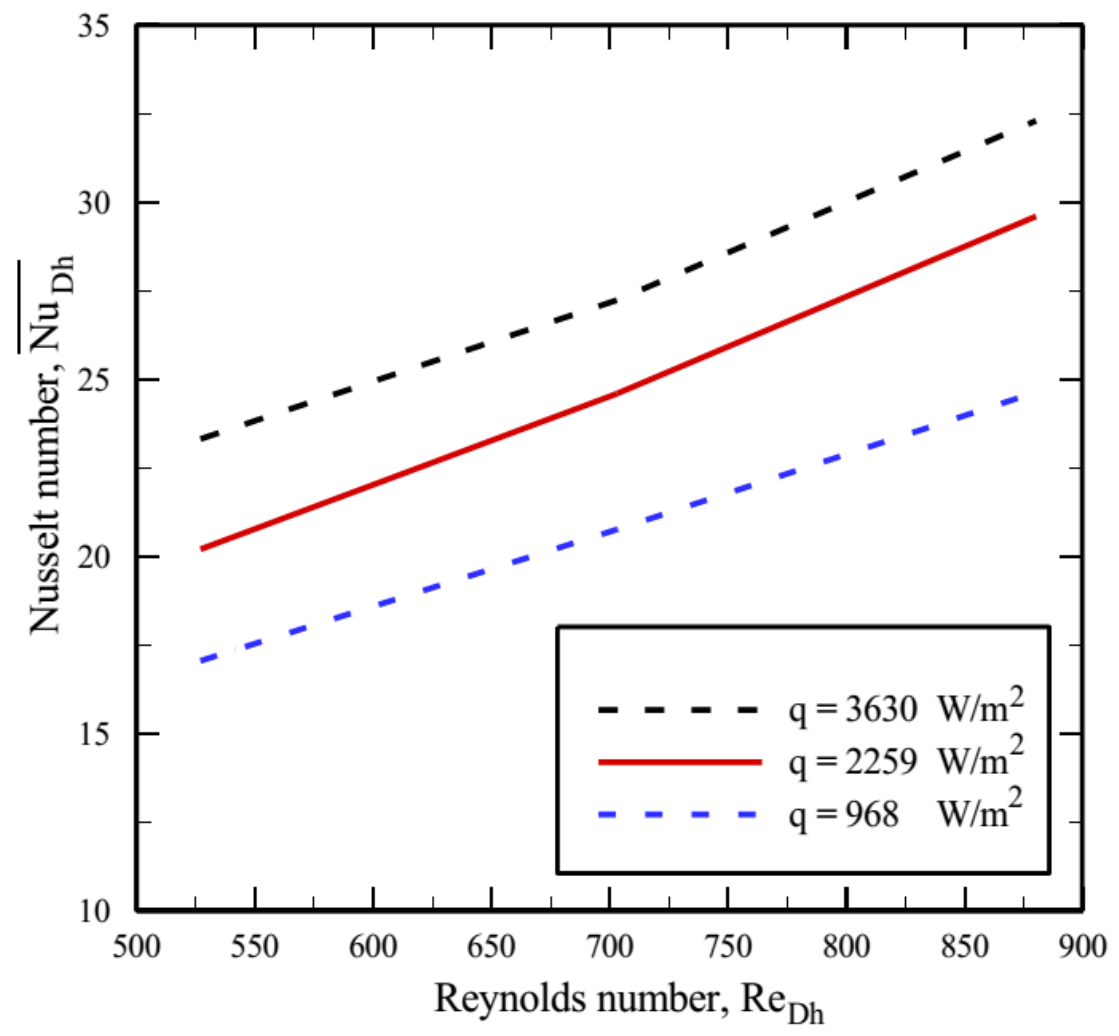

Figure 4. Mean Nusselt number variation versus Reynolds numbers for different heat flux supply. 


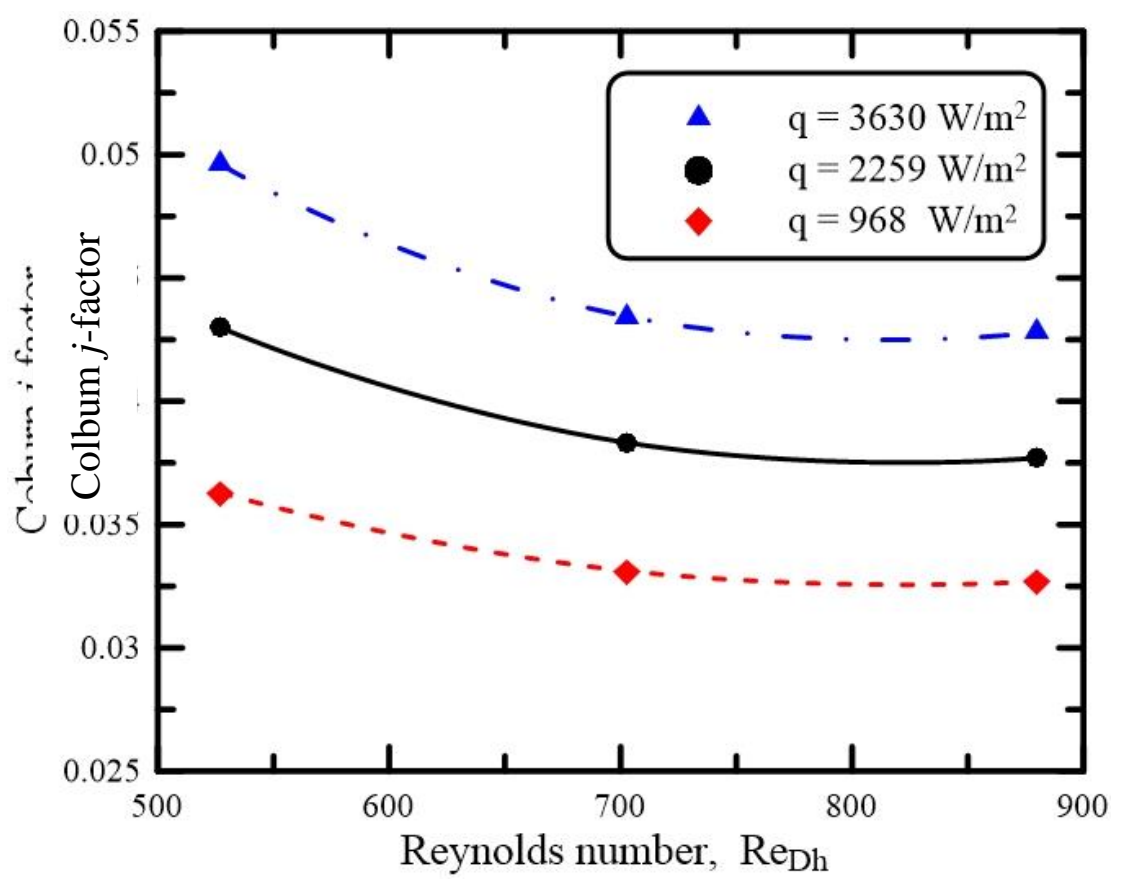

Figure 5. Influence of Reynolds number on the Colburn $j$-factor for several heat flux values supplied.

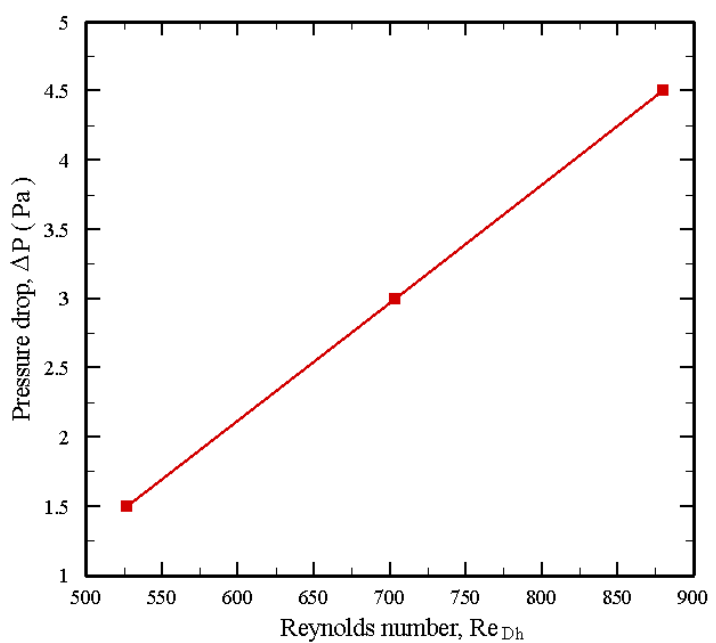

(a)

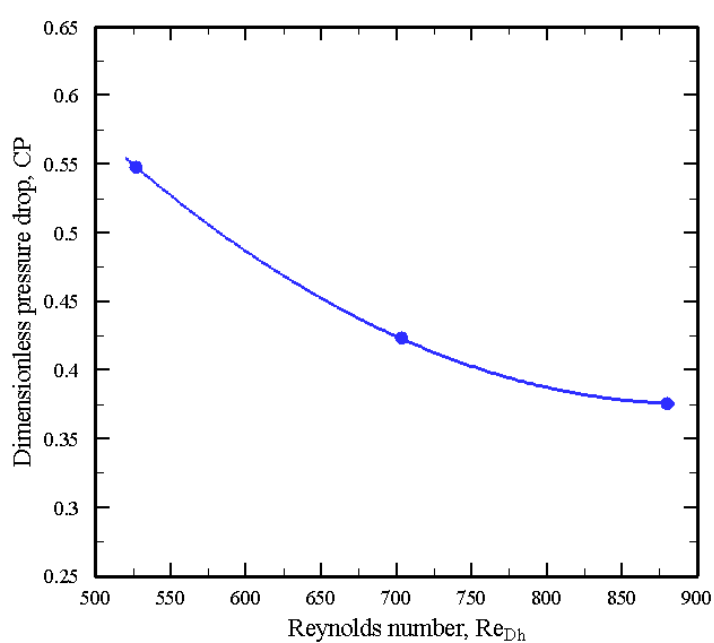

(b)

Figure 6. Variations of pressure drop and dimensionless pressure drop across test section corresponding to Reynolds number.

The variation of pressure drop $\Delta P$ and the dimensionless pressure drop $C P$ with the Reynolds number is shown in Figure 6. It is clear from Figure 6a that the $\Delta P$ increases linearly with increase of the $\operatorname{Re}_{\mathrm{D}_{h}}$ number. The results show that the $C P$ decreases with increase of the $\operatorname{Re}_{\mathrm{D}_{h}}$ number. Figure 7 shows the relationship of the average Nusselt number with the Reynolds number. In addition, the figure shows a comparison of the experimental result with two previous works by Hausen (1983) and Wilson and Bassiouny (2000). The increase of the mean Nusselt number with the increase of Reynolds number in the power law can be formalized as 


$$
\overline{\mathrm{Nu}_{D_{\mathrm{h}}}}=C_{1} \times\left(\mathrm{Re}_{\mathrm{D}_{h}}\right)^{C_{2}}
$$

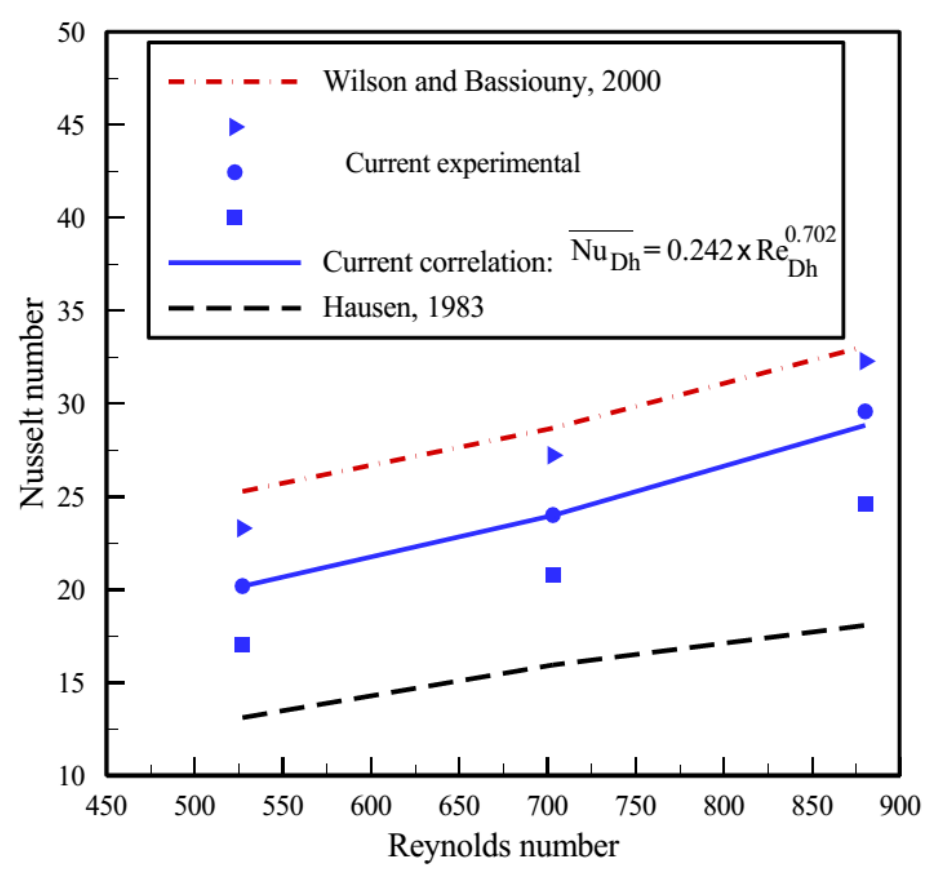

Figure 7. Variations of Nusselt number with Reynolds number and comparison with previous studies and correlation.

\section{CONCLUSIONS}

In this paper, an experimental study of heat transfer and air flow over an in-line flat tube bundle is reported. The study results can be summarized as follows:

i. The average Nusselt number of the air flow increases with the increase of the Reynolds number.

ii. The average Nusselt number of all the flat tubes is increased by $23.7 \%-36.7 \%$ with Reynolds numbers varying from 527 to 880 at fixed heat flux.

iii. The pressure drop increases with increase of the Reynolds number, while the dimensionless pressure drop decreases with increase of the Reynolds number.

iv. Finally, the Nusselt number-Reynolds number correlation was found to be $\overline{\mathrm{Nu}_{D_{\mathrm{h}}}}=0.242 \times\left(\operatorname{Re}_{\mathrm{D}_{h}}\right)^{0.702}$ with a mean error $R^{2}=99.2 \%$.

\section{ACKNOWLEDGMENTS}

This research is part of a Ph.D. project in Mechanical Engineering. The researcher would like to thank the Faculty of Mechanical Engineering, Universiti Malaysia Pahang for providing laboratory facilities and financial support under project no. RDU120103.

\section{REFERENCES}

Akcil, A., \& Koldas, S. (2006). Acid mine drainage (amd): Causes, treatment and case studies. Journal of Cleaner Production, 14(12-13), 1139-1145. 
Al- Doori, W. H. A. R. (2011). Enhancement of natural convection heat transfer from the rectangular fins by circular perforations. International Journal of Automotive and Mechanical Engineering, 4, 428-436.

Ay, H., Jang, J., \& Yeh, J.-N. (2002). Local heat transfer measurements of plate finnedtube heat exchangers by infrared thermography. International Journal of Heat and Mass Transfer, 45(20), 4069-4078.

Aziz Hairuddin, A., Wandel, A. P., \& Yusaf, T. (2013). Effect of different heat transfer models on a diesel homogeneous charge compression ignition engine. International Journal of Automotive and Mechanical Engineering, 8, 12921304.

Buyruk, E., Johnson, M., \& Owen, I. (1998). Numerical and experimental study of flow and heat transfer around a tube in cross-flow at low reynolds number. International Journal of Heat and Fluid Flow, 19(3), 223-232.

Collett, C. V., \& Hope, A. D. (1983). Engineering measurements (2nd ed.). Singapore: ELBS.

Dieck, R. H. (1997). Measurement uncertainty models. ISA transactions, 36(1), 29-35.

Hausen, H. (1983). Heat transfer from tubes in counter flow, parallel flow and cross flow. USA: McGraw-Hill.

Holman, J. P. (2012). Experimental methods for engineers (8th ed.). New York: McGraw-Hill.

Hussein, A. M., Sharma, K. V., Bakar, R. A., \& Kadirgama, K. (2013). Heat transfer enhancement with nanofluids - a review. Journal of Mechanical Engineering and Sciences, 4, 452-461.

Incropera, F. P., Lavine, A. S., \& DeWitt, D. P. (2011). Fundamentals of heat and mass transfer: John Wiley \& Sons.

Ishak, M., Tahseen, T. A., \& Rahman, M. M. (2013). Experimental investigation on heat transfer and pressure drop characteristics of air flow over a staggered flat tube bank in cross-flow. International Journal of Automotive and Mechanical Engineering, 7, 900-911.

Jang, J.-Y., \& Yang, J.-Y. (1998). Experimental and 3-d numerical analysis of the thermal-hydraulic characteristics of elliptic finned-tube heat exchangers. Heat Transfer Engineering, 19(4), 55-67.

Kaptan, Y., Buyruk, E., \& Ecder, A. (2008). Numerical investigation of fouling on cross-flow heat exchanger tubes with conjugated heat transfer approach. International Communications in Heat and Mass Transfer, 35(9), 1153-1158.

Khan, M. G., Fartaj, A., \& Ting, D. S. K. (2004). An experimental characterization of cross-flow cooling of air via an in-line elliptical tube array. International Journal of Heat and Fluid Flow, 25(4), 636-648.

Kim, J. H., Simon, T. W., \& Viskanta, R. (1993). Journal of heat transfer policy on reporting uncertainties in experimental measurements and results. Journal of Heat Transfer, 115(1), 5-6.

Kline, S. J., \& McClintock, F. A. (1953). Describing uncertainties in single-sample experiments. Mechanical Engineering, 75(1), 3-8.

Liang, C., \& Papadakis, G. (2007). Large eddy simulation of cross-flow through a staggered tube bundle at subcritical reynolds number. Journal of Fluids and Structures, 23(8), 1215-1230.

Mandhani, V., Chhabra, R., \& Eswaran, V. (2002). Forced convection heat transfer in tube banks in cross flow. Chemical Engineering Science, 57(3), 379-391. 
Matos, R., Vargas, J., Laursen, T., \& Bejan, A. (2004). Optimally staggered finned circular and elliptic tubes in forced convection. International Journal of Heat and Mass Transfer, 47(6), 1347-1359.

Muthucumaraswamy, R., \& Velmurugan, S. (2013). Heat and mass transfer effects on flow past parabolic started isothermal vertical plate in the presence of first order chemical reaction. Journal of Mechanical Engineering and Sciences, 4, 431-439.

Naga Sarada, S., Sita Rama Raju, A. V., Kalyani Radha, K., \& Syam Sunder, L. (2012). Augmentation of turbulent flow heat transfer in a horizontal tube with varying width twisted tape inserts. International Journal of Automotive and Mechanical Engineering, 6, 797-810.

Naik, S., Probert, S. D., \& Shilston, M. J. (1987). Forced-convective steady-state heat transfers from shrouded vertical fin arrays, aligned parallel to an undisturbed airstream. Applied Energy, 26(2), 137-158.

Persson, A., Hogmark, S., \& Bergström, J. (2005). Thermal fatigue cracking of surface engineered hot work tool steels. Surface and Coatings Technology, 191(2), 216227.

Rao, G. S., Sharma, K. V., Chary, S. P., Bakar, R. A., Rahman, M. M., Kadirgama, K., \& Noor, M. M. (2011). Experimental study on heat transfer coefficient and friction factor of al2o3 nanofluid in a packed bed column. Journal of Mechanical Engineering and Sciences, 1, 1-15.

Rogers, G. F. C., \& Mayhew, Y. R. (2004). Thermodynamic and transport properties of fluids (5th ed.). UK: Blackwell Publishing.

Sahin, B., Manay, E., \& Ozceyhan, V. (2013). Overall heat transfer enhancement of triangular obstacles. International Journal of Automotive and Mechanical Engineering, 8, 1278-1291.

Stanescu, G., Fowler, A., \& Bejan, A. (1996). The optimal spacing of cylinders in freestream cross-flow forced convection. International Journal of Heat and Mass Transfer, 39(2), 311-317.

Suryanarayana, K. V., Srinivasa Rao, G., Reddy Prasad, D. M., Sharma, K. V., \& Sarma, P. K. (2011). Experimental analysis of heat and mass transfer in a packed bed. Journal of Mechanical Engineering and Sciences, 1, 124-132.

Syam Sundar, L., \& Sharma, K. V. (2011). Laminar convective heat transfer and friction factor of al2o3 nanofluid in circular tube fitted with twisted tape inserts. International Journal of Automotive and Mechanical Engineering, 3, 265-278.

Tahseen, T. A., Ishak, M., \& Rahman, M. M. (2012). A numerical study of forced convection heat transfer over a series of flat tubes between parallel plates. Journal of Mechanical Engineering and Sciences, 3, 271-280.

Tahseen, T. A., Ishak, M., \& Rahman, M. M. (2013a). Laminar forced convection heat transfer over staggered circular tube banks: A cfd approach. Journal of Mechanical Engineering and Sciences, 4, 418-430.

Tahseen, T. A., Ishak, M., \& Rahman, M. M. (2013b). A numerical study of laminar forced convection of air for in-line bundle of cylinders crossflow. Asian Journal of Scientific Research, 6, 217-226.

Tahseen, T. A., Ishak, M., \& Rahman, M. M. (2014). Performance predictions of laminar heat transfer and pressure drop in an in-line flat tube bundle using an adaptive neuro-fuzzy inference system (anfis) model. International Communications in Heat and Mass Transfer, 50, 85-97.

Vijaya Lakshmi, B., Subrahmanyam, T., Dharma Rao, V., \& Sharma, K. V. (2011). Turbulent film condensation of pure vapors flowing normal to a horizontal 
condenser tube - constant heat flux at the tube wall. International Journal of Automotive and Mechanical Engineering, 4, 455-470.

Wang, Y. Q., Penner, L., \& Ormiston, S. (2000). Analysis of laminar forced convection of air for crossflow in banks of staggered tubes. Numerical Heat Transfer: Part A: Applications, 38(8), 819-845.

Webb, R. L., \& Kim, N. H. (2005). Principles of enhanced heat transfer (2nd ed.). New York, USA: Taylor \& Francis Group.

Wilson, A. S., \& Bassiouny, M. K. (2000). Modeling of heat transfer for flow across tube banks. Chemical Engineering and Processing: Process Intensification, 39(1), 1-14.

Yianneskis, M., Papadakis, G., Balabani, S., \& Castiglia, D. (2001). An experimental and numerical study of the flow past elliptic cylinder arrays. Proceedings of the Institution of Mechanical Engineers, Part C: Journal of Mechanical Engineering Science, 215(11), 1287-1301.

Zukausras, A. (1973). Heat transfer from tubes in crossfiow. Advances in Heat Transfer, 8, 93-158.

\section{NOMENCLATURE}

\begin{tabular}{|c|c|c|c|}
\hline$A_{s}$ & tube surface area, $\mathrm{m}^{2}$ & $\operatorname{Re}$ & Reynolds number \\
\hline$C_{1}, C_{2}$ & correlation/curve fit coefficients & $T$ & temperature, ${ }^{\circ} \mathrm{C}$ \\
\hline$C P$ & pressure coefficient & $V$ & velocity, $\mathrm{m} / \mathrm{s}$ \\
\hline$c_{P}$ & $\begin{array}{l}\text { specific heat capacity at constant } \\
\text { pressure, } \mathrm{kJ} /\left(\mathrm{kg}{ }^{\circ} \mathrm{C}\right)\end{array}$ & $U$ & voltage, Volt \\
\hline$d$ & transverse diameter of tube, $\mathrm{m}$ & Greeks & \\
\hline$D$ & longitudinal diameter of tube, $\mathrm{m}$ & $\varepsilon$ & emissivity \\
\hline$D_{h}$ & $\begin{array}{l}\text { hydraulic diameter of the flat } \\
\text { tube, } m\end{array}$ & $\Delta P$ & $\begin{array}{l}\text { pressure drop across the tube } \\
\text { array, } \mathrm{Pa}\end{array}$ \\
\hline$f$ & friction factor & $\sigma$ & $\begin{array}{l}\text { Stefan-Boltzmann constant, } \\
5.670373 \times 10^{-8} \mathrm{~W} /\left(\mathrm{m}^{2} \mathrm{~K}^{4}\right)\end{array}$ \\
\hline$I$ & current, A & $\mu$ & dynamic viscosity, $\mathrm{kg} /(\mathrm{m} \mathrm{s})$ \\
\hline$j$ & the Colburn factor & $\rho$ & density, $\mathrm{kg} / \mathrm{m}^{3}$ \\
\hline$h$ & $\begin{array}{l}\text { average heat transfer coefficient, } \\
\mathrm{W} /\left(\mathrm{m}^{2}{ }^{\circ} \mathrm{C}\right)\end{array}$ & Subscrip & \\
\hline$k$ & thermal conductivity, $\mathrm{W} /\left(\mathrm{m}^{\circ} \mathrm{C}\right)$ & $\mathrm{f}$ & air \\
\hline$L$ & total length of the tubes, $\mathrm{m}$ & in & inlet \\
\hline$n_{\mathrm{t}}$ & number of tubes & $\mathrm{f}$ & air \\
\hline$\overline{\mathrm{Nu}}$ & average Nusselt number & out & out \\
\hline $\operatorname{Pr}$ & Prandtl number & s & surface \\
\hline Q & heat transfer rate, $\mathrm{W}$ & $\infty$ & the free stream \\
\hline
\end{tabular}

